\title{
Ciberbullying: El acoso escolar en el ciberespacio e implicancias psicológicas
}

\author{
Orietta Mireya Neyra Castilla ${ }^{1}$ \\ https://orcid.org/0000-0001-5205-0382 \\ Universidad César Vallejo, Perú
}

Cyberbullying: Bullying in cyberspace and psychological implications

Recibido:05-12-2020

Aceptado: 29-04-2021

\section{Cita Recomendada}

Neyra, O., (2021). Ciberbullying: El acoso escolar en el ciberespacio e implicancias psicológicas.

Hamut' ay, 8 (1), http://dx.doi.org/10.21503/hamu.v8i1.2238

\section{Resumen}

El incremento de violencia o agresiones por medio del uso de las tecnologías en este último año ha tenido un incremento sobre todo en el contexto educativo, donde el uso de estas tiene una prevalencia mayor que en años anteriores, debido a que la educación se ha virtualizado. El acoso escolar o bullying que acontecía en las aulas ahora se ha convertido en ciberbullying o acoso en el ciberespacio, porque los medios tecnológicos sirven de canal para estos ataques. El objetivo del artículo es realizar un análisis reflexivo desde la revisión de la literatura acerca del acoso escolar en el ciberespacio conocido como ciberbullying y como este tiene un impacto psicológico en los que están involucrados. El estudio es una revisión bibliográfica realizada en el periodo entre el 2016 a 2021. Se ha llegado a la conclusión de que el ciberbullying es un acoso cibernético que se realiza en diversos medios electrónicos y que genera una afectación negativa mayor en las victimas y que merma su salud mental incidiendo en aspectos psicológicos como baja autoestima, disminución de su autoconcepto, desesperanza, depresión, ansiedad hasta con la posibilidad de llegar al suicidio; y académicamente un bajo rendimiento hasta dejar los estudios.

Palabras Clave: Ciberbullying, acoso escolar, tecnologías, psicológico, depresión 
Abstract

The increase of violence or aggressions through the use of technologies in the last year has had an increase especially in the educational context, where the use of these has a higher prevalence than in previous years, due to the fact that education has been virtualized. The bullying that used to take place in the classroom has now become cyberbullying or harassment in cyberspace, because the technological media serve as a channel for these attacks. Therefore, this article aims to perform a reflective analysis from the literature review about bullying in cyberspace known as cyberbullying and how it has a psychological impact on those involved. The study is a literature review conducted in the period between 2016 to 2021. It has been concluded that cyberbullying is a cyberbullying that takes place in various electronic media and generates a major negative impact on the victims and undermines their mental health affecting psychological aspects such as low self-esteem, decreased self-concept, hopelessness, depression, anxiety and even the possibility of suicide; and academically low performance to the point of dropping out of school.

Key words: Cyberbullying, school bullying, technologies, psychological, depression.

\section{Introducción}

La educación ha tenido una serie de matices en las últimas décadas y siendo una de ellas la violencia escolar que se daba dentro de las aulas, pasando a formar parte de un tema de salud pública en casi todo el mundo, (Marcela et al. 2018). Como también lo refiere la Unicef (2018) en uno de sus estudios que a nivel mundial aproximadamente 150 millones de estudiantes han experimentado violencia dentro y fuera de la escuela, situación que la relacionan de manera directa con el bullying o acoso escolar; como lo describe la UNESCO (2018) que el $31.7 \%$ en EE. UU, 22.8\% en América Central, 30.2\% en Sudamérica, $30.3 \%$ en Asia y un $48.2 \%$ de los estudiantes sufren de bullying en sus instituciones educativas o en su entorno. Pero esta situación no solo está mermando en el clima escolar sino ha traspasado fronteras, al utilizar como otro medio de acoso a las tecnologías de la información y comunicación (TIC) y el ciberespacio se ha convertido en el lugar donde se realiza una violencia cibernética, que la definen como Ciberbullying, (Chaves-Álvarez, Morales-Ramírez y Villalobos-Cordero 2019; Alvites-Huamaní, 2019). Para Gavilán et al., (2020) el ciberbullying es un problema que se ha incrementado al ser una extensión del bullying tradicional.

La preponderancia que ha tenido en este último año el uso de las TIC en este escenario de pan- demia y habiéndose convertido en obligatorio y esencial (Zeynep \& Subhan, 2020) en las diversas esferas académicas, está conllevando a que se agudice el ciberbullying (Gómez-León, 2021), ya que en muchos casos se ha extrapolado situaciones que se presentaban de manera presencial a la virtualidad en la que ahora se está inmerso, debido a las restricciones que se tienen por la emergencia sanitaria, aspectos que no solo han afectado a personas adultas sino a niños, adolescentes y jóvenes sobre todo en el ámbito educativo. En este contexto el ciberbullying no solo se realiza en un solo escenario sino utiliza diversos medios desde plataformas digitales hasta redes sociales como Facebook, Twitter, Instagram, WhatsApp entre las más utilizadas.

\section{Método}

El estudio que se presenta es de tipo documental, se realizó una revisión de la literatura en diversas bases de datos como Web Of Science, Scopus, Scielo, Dialnet y EBSCO. Para que la búsqueda sea lo más específica posible, se consideró un periodo entre 2016 al 2021, de los cuales se obtuvieron un promedio de 98 textos, considerando criterios de inclusión que estos tuvieran una relación con el ciberbulllying y como implicancias lo psicológico por lo que se seleccionaron 33 de ellos, los cuales fueron analizados y descritos en las variables de estudio de esta revisión bibliográfica. (Figura 1). 
PORCENTAJES DE ARTÍCULOS ANALIZAdOS POR AÑo

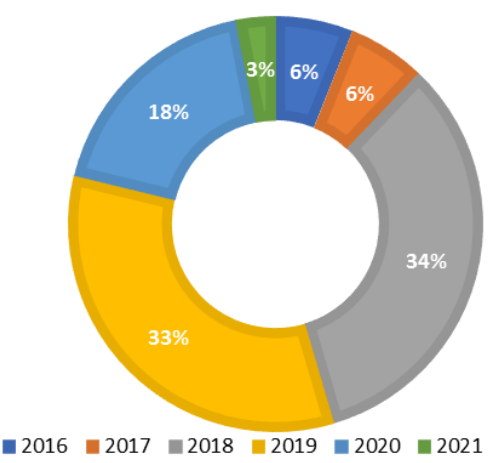

Figura 1. Porcentajes de artículos analizados entre 2016 y 2021.

Fuente: Elaboración propia (2021)

Para realizar la búsqueda adecuada se utilizaron palabras claves, tales como: Ciberacoso, violencia en línea, ciberbullying en pandemia, acoso escolar en línea, cibervictimización, ciberagresor, efectos psicológicos ciberbullying, Cyberbullying.

\section{El acoso escolar en el ciberespacio}

La violencia entre pares que se observaba en las escuelas y se hacía palpable en el bullying o acoso escolar estaba en aumento, por lo que las autoridades se vieron obligadas a imponer sanciones drásticas (Gavilán et al., 2020), hasta llegar a imputaciones penales, lo cual en algo favoreció para que este problema fuera decreciendo. Pero con la llegada de la pandemia y cuando se creía que esto pasaría a un segundo plano por la cuarentena y confinamiento y por los cambios abismales que generó en los diversos ámbitos a nivel mundial (Alvites-Huamaní, 2020), esto no ha sido así, ya que este acoso escolar se convirtió en un acoso cibernético o como muchos autores lo definen como ciberbullying, y lo consideran un mal derivado de la sociedad de la información y las TIC (Broll, 2016), ya que su fin es acosar y dañar a otra persona por medio de las plataformas y medios digitales.

Para López, Quezada \& Carrillo (2018) el ciberbullying es el uso deliberado de los medios tecnológicos para mandar mensajes, videos o publicar imágenes ofensivas por las redes sociales, buscando humillar a sus víctimas. De manera similar, Kavuk \& Keser (2018) consideran al ciberbullying como la agresión cibernética donde el agresor de manera anónima da rienda suelta a sus maltratos y hostigamientos a una cibervíctima.

Según Matos et al. (2018) el ciberbullying es el acoso entre pares en el ciberespacio, visualizándose conductas como el chantaje, injurias, burlas y que afectan a la dignidad de la persona, sin importar su edad, sexo, opción sexual, nivel socioeconómico. etc.

Torres-Montilla, Mejía-Montilla y Reyna-Villasmil (2018); Lacunza et al., (2019) refieren que la violencia que se realiza con el uso de las tecnologías tiene una connotación de ciberacoso, acoso cibernético, agresión en línea, intimidación y acoso por internet, victimización cibernética o agresión electrónica, y esto se da porque los jóvenes hacen un uso más constante de los medios tecnológicos, el internet y las redes sociales, (Ruíz-Martín, Bono-Cabré y Magallón-Neri, 2019).

Pero lo cierto es que este fenómeno se sirve de las tecnologías, pero de una forma no adecuada porque conlleva a un comportamiento negativo, repetitivo a lo largo del tiempo, dentro de una relación desigual de poder, en la que están involucrados ciberacosadores y cibervíctimas. Meter \& Bauman (2018) refieren que el agresor tiene como objetivo provocar un daño psicológico en su víctima, a través de enviar contenidos dañinos en las redes sociales u otro tipo de medio tecnológico, que una vez que ingresa a la red es casi imposible de eliminar y en cuestión de segundos se hace viral. Por su parte Carretero y Gimeno (2019) describen algunas características del acosador, como es usual que ataque a personas de edad similar a él, en la mayoría de los casos se conoce de alguna manera con la víctima, pudiendo ser compañeros del mismo centro educativo, amigos de barrio, etc., pero también pueden ser desconocidos porque utilizan las redes sociales de acceso abierto, dan cabida a que estas terceras personas formen parte de su vínculo de conocidos (Lacunza et al., 2019).

En su mayoría, son los jóvenes en edad escolar y universitaria quienes usan las tecnologías (Do- 
mínguez-Mora, 2019) para socializar, interactuar con sus pares, comunicarse, entre otros aspectos relevantes (Blanco, González y Velasco, 2020), lo cual ha generado una convivencia digital y lo que ha conllevado a que ostenten una identidad digital en la que hacen una descripción de ellos mismos en el plano digital (López y Sánchez, 2019), la cual puede ser real o ficticia.

Machimbarrena et al. (2019) refieren que hoy en día las tecnologías han alcanzado un gran impacto en la sociedad sobre todo en los más jóvenes, que día a día emplean estas para interactuar con sus pares por medio de las redes sociales y diversos canales de comunicación virtual, pero no solo las utilizan de una manera adecuada y positiva, (Gargallo \& Galve, 2017) sino que en muchas ocasiones le dan un mal uso a estos medios tecnológicos sirviéndose de ellos para insultar, burlarse u ocasionar un tipo de violencia más dañina. Alvites-Huamaní (2019) manifiesta que estas agresiones se pueden suscitar de una manera permanente y continúa exponiendo estas a la vista de todo el mundo que navega en el ciberespacio, teniendo el respaldo del anonimato para seguir transgrediendo las normas, puesto que son conscientes que al no saber su identidad no habrá repercusiones sobre ellos, al no poder ser identificados fácilmente, dando rienda suelta al ciberacoso.

Gómez, Sánchez \& Pérez (2017) expresan que las TIC han desencadenado un uso desmedido de estos medios al haber evolucionado el bullying o acoso escolar a un acoso en línea o ciberacoso o ciberbullying (Alvites-Huamaní, 2019), en el cual miles de usuarios que navegan en estas redes sociales tienen acceso a todo tipo de contenido sin algún tipo de filtro o censura que prohíba o advierta de su riesgo.

El ciberbullying o acoso cibernético como coinciden algunos investigadores, es el que acontece como agresión mediante el uso de las TIC. (Figura 2).

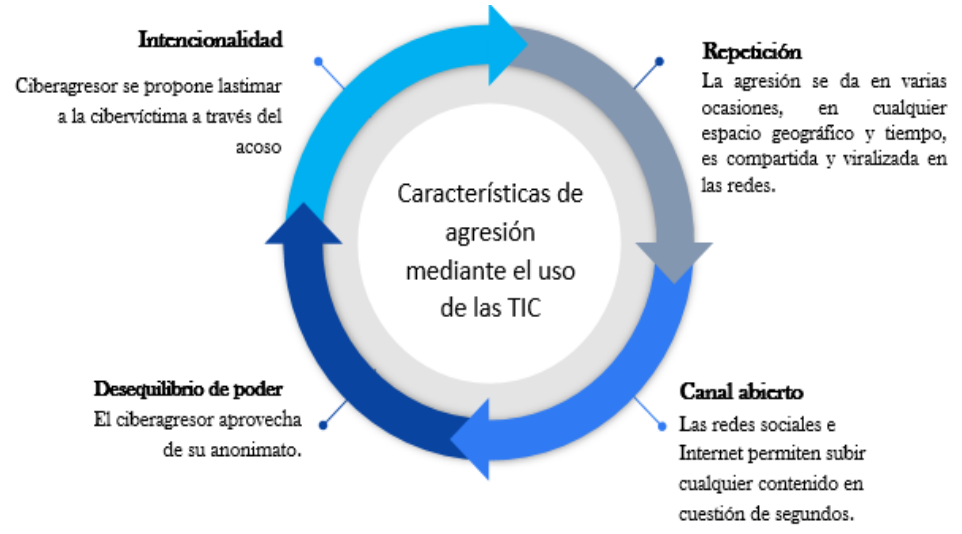

Figura 2. Característica de agresión mediante el uso de las TIC. Fuente: Adaptado de Domínguez y Portela, 2020; Domínguez-Mora et al., 2019; Magaz et al., 2016.

En el ciberbullying el acoso cibernético se puede presentar instantáneamente, debido a que los mensajes, imágenes y videos son muy sencillos de subir a las redes y en cuestión de segundos ingresan al ciberespacio, en este punto, las víctimas son vulnerables a comentarios ofensivos, burlas imparables, suplantación de identidad, etc., ya que un gran porcentaje de las víctimas han sido hackeadas o han sido víctimas de hurtos de sus celulares (lugar donde suelen guardar archivos íntimos), siendo estas difundidas sin permiso con el único objetivo de dañar su integridad, (Cuesta et al., 2020) y exponerlas a agresiones, hostigamientos, humillaciones y burlas, (Cañizal (2018) durante los 365 días del año y las 24 horas del día, (Alvites-Huamaní, 2019).

\section{Impacto psicológico del ciberbullying}

En una época donde la salud mental de la población a nivel globalizada esta trastocada por la pandemia, la cual ha incentivado la desesperanza, la preocupación e inseguridad por no tener un futuro alentador; a pesar de ello la violencia a través de las tecnologías se hecho más palpable en los adolescentes y jóvenes por estar más expuestos a estos medios (Gómez-León, 2021; Alvites-Huamaní, 2019), los cuales implican discriminación, abuso de poder, acciones de dominancia e incide en riesgos a nivel psicológico, social hasta físico, (Domínguez y Portela, 2020). Para Torres-Montilla, Mejía-Montilla y Reyna-Villasmil, (2018) la violencia que se realiza 
con las tecnologías y medios electrónicos inciden potencialmente en la salud mental de quien la padece, al producir estrés emocional, ansiedad social, baja autoestima, depresión con una vinculación con tendencias suicidas, además genera respuestas negativas de ira, miedo e impotencia. Rodríguez (2018) afirma que aquellos que son afectados por el ciberbullying como víctimas su autoconcepto y autoestima no son las más óptimas, debido a que las agresiones son repetitivas y constantes por la facilidad que tiene las TIC y los medios electrónicos de expandirlos, enfatiza que las cibervíctimas fácilmente se sumerjan en un estado de depresión, llegando en algunos casos a quitarse la vida, por no soportar tanto acoso y hostigamiento en la red (Tajahuercel y Juárez, 2018).

Rivadulla y Rodríguez (2019) mencionan que aquellos que son cibervíctimas no tienen una aceptación entre sus iguales, por ende, sufren de baja autoestima, depresión y aislamiento social, además carecen de habilidades interpersonales idóneas para hacer frente a situaciones conflictivas que se le presenten. Resett, (2019) resalta que la cibervictimización y ciberagresión que se presenta en el ciberbullying comprende problemas psicológicos como depresión, ansiedad y en algunos casos llegan hasta el suicidio en las víctimas, en los agresores tienden a tener una mayor conducta antisocial y desinhibición por el anonimato que le respalda los medios tecnológicos al acosar.

Gómez-León (2021) enfatiza que en la pandemia los adolescentes pasan un mayor tiempo navegando en Internet por lo que el ciberbullying se debe haber acentuado.

Chaves-Álvarez, Morales-Ramírez y Villalobos-Cordero (2019) refieren quienes son más afectados al ser violentados a través del ciberbullying es la víctima debido a que va a tener repercusiones en su salud mental y aumentará el trauma emocional y físico, ocasionando en muchos casos sentimientos de culpa como si él o ella fueran los responsables de lo que les ocurre, descuida su imagen personal, retraimiento, conductas violentas o suicidas.

Cañizal (2018) enfatiza para que se hable de ci- berbullying debe haber una relación de poder entre la cibervíctima y ciberacosador de dominio-sumisión, que las agresiones deben ser reiterativas y los actos deben ser intencionados o planificados y con ello se dan ciertas conductas de acoso (Figura 3) a través de dispositivos electrónicos o por Internet.
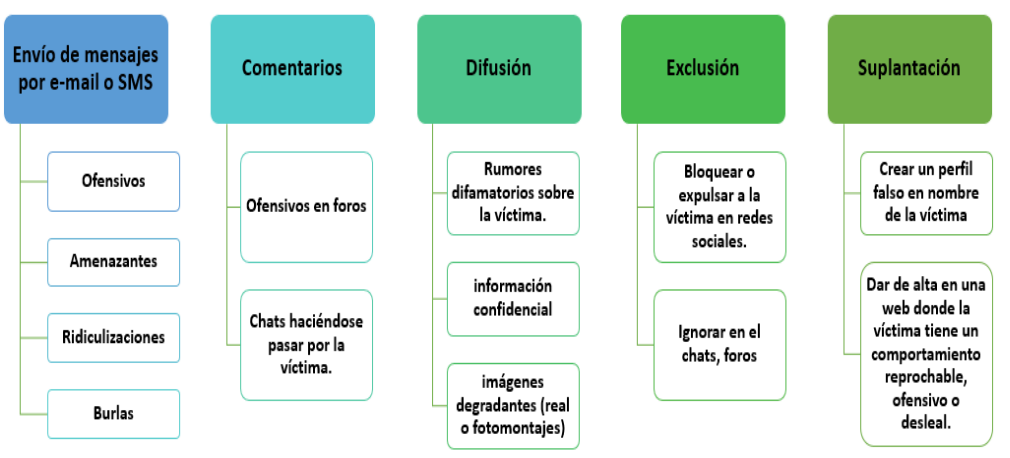

Figura 3. Conductas de acoso cibernético o ciberbullying Fuente: Adaptado de Cañizal, 2018

Adicional a los problemas psicológicos que puedan tener tanto las víctimas como los agresores, Girgin (2019) expone que son las victimas las más perjudicadas, debido a que tendrá un bajo rendimiento, en muchos casos deserción, afectará su estilo de vida y aprendizaje, puede llevar a que caiga en algún tipo de adicción como el consumo de sustancias psicoactivas (drogas, alcohol, etc.) las cuales son perjudiciales para su salud.

El sufrir de un constante hostigamiento en el ciberespacio, conlleva a que las víctimas presenten cuadros depresivos teniendo comorbilidad con otros problemas psicológicos, en el cual la autoestima e integridad de la persona se ve severamente vulnerada, implicando que las relaciones con su familia se deterioren aislándose de ellos, esta situación se puede complicar si en el hogar no existe buena comunicación entre sus miembros o no hay una cohesión familiar.

\section{Conclusiones}

El ciberbullying es realizar hostigamiento por medio de las tecnologías de la información y la comunicación, principalmente Internet siendo esta modalidad la manera más común y frecuente de acoso. Además, es considerado una extensión del denominado acoso escolar o bullying que es 
una forma de violencia escolar que se gesta en línea, en el cual uno o varios agresores de manera intencionada acosan constantemente a una víctima con ataques repetitivos, constantes durante un tiempo indeterminado, para lo cual utilizan los recursos digitales más comunes como son el chat, mensajería, correo electrónico, las redes sociales, situando a la víctima en un estado de indefensión.

Los diversos autores que se han analizado en este estudio muestran la complejidad del acoso que se realiza en línea, donde se observa que el más afectado es la víctima, porque tiene daños severos en lo psicológico, en su estado de ánimo y en su ámbito académico, ya que este último tiene una repercusión directa con su rendimiento académico, así también sus relaciones sociales con sus pares y su entorno se ven resquebrajada por su alejamiento y aislamiento.

El cyberbullying surge como un fenómeno derivado de la sociedad de la información y las tecnologías al tener una prevalencia en uso, sobre todo en los adolescentes y los jóvenes, ya que su mundo son las redes sociales y el ciberespacio, pero algunos aprovechan estos medios para incitar a la violencia y agresión o hacer uso de ella, por considerarse omnipotentes por el anonimato que le permite estas herramientas o aparatos electrónicos.

Muchos de los jóvenes que utilizan estos medios virtuales de manera negativa, y que originan violencia virtual, no tienen una idea de que tanto afectan la salud mental de la persona que son víctimas de ellos, cuanto dolor les causan llevándolos hasta la depresión, pensamientos suicidas, ansiedad, estrés y desesperanza, aunado a ella la baja autoestima y autoconcepto que tienen de ellos mismos.

Para futuros temas relacionados con el ciberbullying se recomienda que se analice que programas de intervención se están aplicando para las víctimas como para los agresores, cual es el rol que cumplen los padres de familia, así como las instituciones educativas, con la finalidad de que no siga en ascenso este tipo de violencia y erradicarla del todo entre los estudiantes, más aun en estos tiempos en que las tecnologías van a seguir for- mando parte de nuestra vida cotidiana en el contexto educativo. También sería importante realizar un análisis de aspectos sociodemográficos y culturales del ciberbullying entre Latinoamérica, Centroamérica y Europa y además conocer cuál de todas las redes sociales tienen un mayor porcentaje de uso para realizar ciberbullying.

\section{Referencias Bibliográficas}

Alvites-Huamaní, C. (2020). COVID-19: Pandemia que impacta en los estados del ánimo. CienciAmérica, 9(2). Número Especial. https://doi. org/10.33210/ca.v9i2.327

Alvites-Huamaní, C. (2019). Adolescencia, ciberbullying y depresión, riesgos en un mundo globalizado. Revista científica electrónica de Educación y Comunicación en la Sociedad del Conocimiento, 19 (1), 210-234. https://doi. org/10.30827/eticanet.v19i1.11867

Blanco, S., González, C. y Velasco, J. (2020). Nuevas herramientas para viejos problemas: acoso $\mathrm{y}$ ciberacoso a través de un análisis de sentencias. Tecnología, Ciencia y Educación, 15, 51-80. https://doi.org/10.51302/tce.2020.367

Broll, R. (2016). Collaborative responses to cyberbullying: Preventing and responding to $\mathrm{cy}-$ berbullying through nodes and clusters. Policing \& Society, 26(7), 735-752.

https://doi.org/10.1080/10439463.2014.989154 Cañizal, F. (2018). Ciberbullying en Educación Secundaria: ¿Un problema escolar? (Tesis de Máster). Universidad de Cantabria. España.

Carretero, C. y Gimeno, E. (2019). Estudio de un modelo predictivo del clima escolar sobre el desarrollo del carácter y las conductas de bullying. Estudios Sobre Educación, 37, 135-157. https:// doi.org/10.15581/004.37.135-157

Chaves-Álvarez, A., Morales-Ramírez, M. y Villalobos-Cordero, M. (2019). Ciberbullying desde la perspectiva del estudiantado: "Lo que vivimos, vemos y hacemos". Revista Electrónica Educare, 24(1), 1-29.

https://doi.org/10.15359/ree.24-1.3

Cuesta, L., Hennig, C., Lady, Duque, L., \& Malfasi, S. (2020) Cyberbullying: tackling the silent enemy. International Journal of Inclusive Educa- 
tion, 24(9), 936-947.

https://doi.org/10.1080/13603116.2018.1500648

Domínguez, J., y Portela, I. (2020). Violencia a través de las TIC: comportamientos diferenciados por género. RIED. Revista Iberoamericana de Educación a Distancia, 23(1), 273-286. https://doi.org/10.5944/ried.23.2.25916

Domínguez-Mora, R., Vargas-Jiménez, E., Castro-Castaneda, R., Medina-Centeno, R., \& Huerta-Zúñiga, C. G. (2019). Ciberacoso como factor asociado al malestar psicológico e ideación suicida en adolescentes escolarizados mexicanos. Acta Universitaria 29, e2295. https://doi. org/10.15174/au.2019.2295

Gargallo, A., \& Galve, C. (2017). Family involvement and the impact of information and communication technology on performance. Academia, 30(1), 23-39.

https://doi.org/10.1108/ARLA-08-2015-0214

Gavilán, D., Merma, G., Urrea, M. y Martínez, R. (2020). Violencias múltiples en el espacio escolar: La travesía hacia la violencia de género. Revista Educativa Hekademos, 29, 1-11.

Girgin, C. (2019). Forgiveness and cyberbullyıng in Turkısh adolescents. Academic Journals, 14(14), 512-517. https://doi.org/10.5897/ ERR2019.3786

Gómez-León, M. (2021). Disminución de la ansiedad en las victimas del bullying durante el confinamiento por COVID-19. Revista de Educación a Distancia, 65(21).

https://doi.org/10.6018/red.439601

Gómez, J., Sánchez, I., \& Pérez, M. (2017). Education in human rights: ethical-civic formation of the social educators as way to anticipate the ciberbullying. Pedagogía Social, (30), 181-194. http:// dx.doi.org/10.SE7179/PSRI_2017.30.13

Kavuk, M. \& Keser, H. (2018). Cyberbullying awareness in secondary and high schools. World Journal on Educational Technology: Current Issues, 10(4), 25-36.

https://doi.org/10.18844/wjet.v10i4.3793

Lacunza, A., Contini, N., Caballero, S. y Mejail, S. (2019). Agresión en las redes y adolescencia: estado actual en américa latina desde una perspectiva bibliométrica. investigación \& desarrollo, 27(2), 6-32. https://doi.org/10.14482/indes.27.2.020.72
López, M.C. y Sánchez, C. (2019). La interacción y convivencia digital de los estudiantes en las redes sociales. Revista de Educación Inclusiva, 12(2), 114-130.

López, L., Quezada, M., \& Carrillo, J. (2018). Manifestations of violence among students of higher education: The uses of WhatsApp. Alteridad, 13(2), 204-213. https://doi.org/10.17163/alt. v13n2.2018.04

Marcela, Y., Guerrero, E., Córdoba, C., Rincón, K., Bustos, J., López, A \& López, J. (2018). Percepción de violencia desde escolares de dos instituciones educativas de la localidad de kennedy, bogotá. Revista De Salúd Publica, 20(4), 438. https://doi.org/10.15446/rsap.v20n4.61085

Magaz, A., Santed, M, Valiente, R., \& Sandín, B. (2016). Evaluación del bullying como victimización: Estructura, fiabilidad y validez del cuestionario de acoso entre iguales (CAI). Revista De Psicopatología y Psicología Clínica, 21(2), 77-95. https://doi.org/10.5944/rppc.vol.21. num.2.2016.16990

Machimbarrena, J., González, J., \& Garaigordobil, M. (2019). Variables familiares relacionadas con el bullying y el cyberbullying: una revisión sistemática. Pensamiento Psicológico, 17(2), 3756. https://doi.org/10.11144/doi:10.11144/Javerianacali.PPSI17-2.vfrb

Matos, A., Vieira, C., Amado, J. Pessoa, T. \& Martins, M. (2018). Cyberbullying in Portuguese Schools: Prevalence and Characteristics. Journal of School Violence, 17(1), 123-137. https://doi.or g/10.1080/15388220.2016.1263796

Meter, D., \& Bauman, S. (2018). Moral disengagement about cyberbullying and parental monitoring: Effects on traditional bullying and victimization via cyberbullying involvement. The Journal of Early Adolescence, 38(3), 303-326. https://doi.org/10.1177/0272431616670752 Resett, S. (2019). Bullying y cyberbullying: su relación con los problemas emocionales y la personalidad. Apuntes de Psicología, 37(1), 3-12. https://doi.org/10.24310/espsiescpsi.v12i2.10060 Rivadulla J. C., y Rodríguez, M. (2019). Ciberacoso escolar: experiencias y propuestas de jóvenes universitarios. RIED. Revista Iberoamericana de Educación a Distancia, 22(2), 179-201. https:// 
doi.org/10.5944/ried.22.2.23541

Rodríguez, A. (2018). Influencia del ciberbullying en la autoestima de los estudiantes de primeros años de bachillerato general unificado de la unidad educativa Pimampiro, cantón Pimampiro. (Tesis de pregrado), Universidad Técnica del Norte, Ecuador. http://bit.ly/3hHCWU4

Ruíz-Martín, A., Bono-Cabré, R. y Magallón-Neri. E. (2019). Ciberacoso y ansiedad social en adolescentes: una revisión sistemática Revista de Psicología Clínica con Niños y Adolescentes, 6(1), 9-15. https://doi.org/10.21134/rpcna.2019.06.1.1 Torres-Montilla, Y., Mejía-Montilla, J. y Reyna-Villasmil, E. (2018). Características del ciberacoso y psicopatología de las víctimas. Repertorio de Medicina y Cirugia, 27(3), 189-196. https://doi.org/10.31260/RepertMedCir.v27. n3.2018.213

Tajahuercel, I., y Juárez, J. (2018). Ciberbullying y género: Nuevos referentes en la ocupación de los espacios virtuales. Estudios Sobre El Mensaje Periodístico, 24(2), 1845-1859. https://doi. org/10.5209/ESMP.62250

Unicef, (2018). An everyday lesson: \#ENDviolence in Schools. Unicef for every child. Recuperado de https://www.unicef.es/sites/unicef.es/files/comunicacion/STOPViolencia_Infantil_Informe_ EMBARGADO_hasta_las_00.01_GMT_6_September2018.pdf

UNESCO (2018). School violence and bullying: Global status and trends, drivers and consequences. United Nations Educational, Scientific and Cultural Organization, France. Recuperado de http://www.infocoponline.es/pdf/BULLYING. pdf

Zeynep, D. \& Subhan E. (2020). Prospective Teachers' STEM Awareness and Information Conmunication Technologies Usage Levels. MOJET, 1(8), 67-85.

https://doi.org/10.17220/mojet.2020.04.005 